\title{
The influence of Worldskills technologies on the formation of professional competence of college students
}

\author{
Valeriya Valerievna Tropnikova ${ }^{1}$ \\ Novosibirsk State Pedagogical University, Department of Chemistry, Institute of Natural and Socio- \\ Economic Sciences, Novosibirsk, Russia
}

\begin{abstract}
The international experience shows that the mechanism of the WorldSkills competitive movement contributes to the development of the vocational education system. The study aimed to consider the Russian competition movement Worldskills Russia (WSR), as part of the international movement in terms of research problems: what is the pedagogical potential of WSR technologies and how effectively it provides the formation of the necessary professional and general competencies of students of secondary vocational institutions in blended learning (for example, medical college). The subject of the analysis was Russian and foreign research related to the formation of the competition movement; special attention was paid on materials that reveal the use of WSR technologies in educational institutions of the secondary vocational education system. The questionnaire was used to get students' vision of WSR, their motivation for participating in the WSR. It was determined that the development processes of WSR included: the formation of the legislative framework; the allocation and use of significant state budget funds for professional training of teachers with the receipt of certificates of WSR Experts; significant costs for conducting exams according to the WSR standard, aimed at increasing the competitiveness of specialists for the innovative economy of the Russian Federation. A survey of medical college students shows that the involvement of the student audience in professional competitions is not ubiquitous; only $24.6 \%$ of first-year students of the first-year vocational education system are informed about the WSR movement. Only $16.9 \%$ of students were motivated to participate in Worldskills competitions. The integration of Worldskills technologies into the educational process in the blended learning model, along with project activities, ensures the formation of the necessary professional and general competencies of students of secondary vocational institutions. Methodological guidelines for the practice of vocational education in preparation for Worldskills require the solution of a set of related pedagogical and didactic problems. The research results can be used in the educational process of the secondary vocational education system.
\end{abstract}

Keywords: Worldskills, blended learning, chemistry, secondary vocational education system

${ }^{1}$ Corresponding author: tropnikova@inbox.ru 


\section{Introduction}

One of the effective world educational guidelines that meet the needs of the innovative educational doctrine in the training of competitive specialists is the use of the potential of the Worldskills competition movement, due to which the demand factor formed by employers for the demanded and predicted professions will be satisfied. According to the Industry 4.0 Global Survey, covering nine large industrial sectors and 26 countries, the issues of activity in industrial ecosystems and training are acute [1]. The results of the implementation of the goals of state policy in the field of education are different, but the essence boils down to demonstrating the importance of vocational education as a tool for socio-economic transformations [2]. Comparing training levels, assessing its quality and identifying the core of skills that remain stable in an era of uncertainty and blurring of professional boundaries is a particular problem [3, 4]. The fusion of European labor markets should provide learners not only with skills, but also with skills such as flexibility and mobility to address the challenges of international cooperation in labor markets [5]. Measuring competencies, evaluating the effectiveness of training programs is possible according to certain criteria. WorldSkills provides new opportunities for a comparable assessment of results in vocational education [6]. The influence of the competitive environment on skill development in on-the-job learning has shown that the more "expansive" the work environment, the more skills [7]. The most important factor influencing the achievements of students is the additional training of experts in the preparation of competitors. Note that in the UK, the WorldSkills movement, funded by the state budget, is viewed as a key instrument of public policy. The annual number of participants is 15.5 thousand students, competitions are held in 60 competencies, including 9 competencies for students with disabilities [8]. WorldSkills Competition (WSC) makes it possible to evaluate the level and degree of competence of specialists at the national level [9]. Pylväs \& Nokelainen (2017) studied the experience of the WorldSkills Competition (WSC), from the part of competition participants, expert trainers and employers [10]. In addition to special professional knowledge and skills, when participating in world-class competitions, additional skills are formed, such as: creativity, social skills and selfregulation skills. A feature of formal vocational education in preparation for competitions was the improvement of long-term career growth. The Russian experience of WorldSkills, which began in 2012, testifies to the currently formed regulatory and legal framework for the education sector. Professional training of teachers was carried out with the receipt of certificates of Worldskills Russia Experts. The new Federal State Educational Standard for 50 in-demand professions (TOP-50) and the WorldSkills technology contributed to intensive changes in the SPE system [11]. WorldSkills practice forms universal competencies, solving problems with the help of cognitive tools, combining professional skills, the presence of competencies in the field of STEM [12]. In 2019, the regions of Russia and the Novosibirsk region, including, accredited specialized centers of excellence. Despite significant costs, the demonstration exam was conducted in 81 regions, covering 1265 educational institutions. A review of Russian studies has shown that attention is focused on various aspects of the achievements of the Worldskills competition movement [13-15]. The researchers believe that the influence of Worldskills - technologies contributes to the formation of not only professional, but also supra-professional competencies necessary for workers at the stage of a significant technological leap, which is commonly called the fourth industrial revolution [16]. As a hypothesis, it is suggested that the competitive movement "warms up" interest in professional activity and promotes increased motivation to study the necessary disciplines. The study aimed to consider the influence of WS technologies on the formation of the necessary competencies of students of secondary vocational institutions with blended learning (for example, a medical college). 


\section{Methods}

The methodological basis of the study was the provisions of the "system-activity approach. The blended learning technology was used within the framework of the flipped class" with the integration of massive open online courses (MOOCs) provided by the Russian platform "Open Education" and Worldskills technology to prepare first-year students in the discipline "Chemistry" to participate in the competitive movement in the competence R 2 "Laboratory medical analysis". A survey was conducted to determine knowledge about the WSR competition movement, motivation to participate in WSR, the formation of students' general and professional competencies in the discipline "Chemistry".

\section{$3 \quad$ Results}

In the conditions of the GAPOU NSO "Novosibirsk Medical College", for the training of specialists majoring in "Medical laboratory technician" specialty 31.02.03 "Laboratory diagnostics" of the SPE system, practical tasks were included taking into account the Federal State Educational Standard, WSR standards and professional standards in the field of knowledge, skills and practical experience in the disciplines "Chemistry" to prepare the 1st year students for the WSR demonstration exams in competence R 2 "Laboratory medical analysis". The required characteristics of the laboratory technician were coordinated with the Professional Module PM.01-06; General competences (GC 1-14), Professional competencies (PC 1.1-1.4; 2.1-2.5; 3.1-3.4; 4.1-4.4; 5.1-5.5; 6.1-6.5.) and Labor functions (A / 04.5; B / 02.6) Professional standard. Blended learning of the "flipped class" model was used with the integration of MOOC resources, which made it possible to adjust the content of the educational program, provide multimedia content with relevant materials on achievements in the field of natural sciences, increasing the effectiveness of learning and student engagement in project activities.

The assessment of competencies was carried out by a survey using:

- Google-form with a convenient and understandable interface;

- a deductive method with the identification of private empirical data by providing respondents with general questions that highlighted the attitudes, knowledge of students and possible motives for participating in the socially significant activities of a laboratory diagnostician.

The survey involved college students of three groups majoring in "Laboratory diagnostics". The sample size of 65 students possessed a fairly high accuracy, covering only representatives of the student audience of this area of the medical college. The questions were divided into blocks, checking the competence of students, readiness for professional activity and competitive movement. $81.5 \%$ of females and $18.5 \%$ of males were interviewed. The age of the students ranged from 17 to 55 . It was determined that less than half of the students know about the goals of the Worldskills Russia competition movement. Not informed about the WSR movement $-24.6 \%$ of students. Only $16.9 \%$ of students are motivated to participate in the WSR competition movement. Questions form the "Know" block related to professional activities, in general, testified to the presence of professional competencies in future laboratory technicians. For example, 95.4\% of students responded positively to the need for certification in order to carry out professional activities. The question of chemical macro- and micro- research, with the possibility of multiple choice of answers, indicates that students are aware and imagine what kind of biological material they will work with in real conditions. The question about the need to control the quality of the research performed for the accuracy and reliability of the results obtained was answered positively by $96.9 \%$ of students. The second block of questions named "Can" showed that not all students have fully mastered the necessary professional 
competencies. $75.4 \%$ of students have mastered various methods of research. The risks of professional activity were assessed by $49.2 \%$ of students; $36.9 \%$ of the respondents highlighted the risks associated with blood tests in patients with hepatitis and HIV-infected. Practical application of the knowledge gained on the effectiveness of sterilization of instruments was mastered by $29.2 \%$ of students. General competencies are partially formed. Assessment of the understanding of responsibility for people's lives during the diagnostic study showed that $96.9 \%$ of students mastered the Rules of work in clinical diagnostic laboratories. A block of questions about the personal characteristics of laboratory technicians, which are in demand when researching difficult epidemiological conditions, showed that more than half of the surveyed students identified "over-professional skills," such as the ability to adapt to changing working conditions under conditions of uncertainty. The key question about the possibility of obtaining the formed competencies of a laboratory diagnostician indicates that $89.2 \%$ of students are sure that it is possible to "learn" to be a professional in their activities. What skills do students want to acquire before starting their professional careers? Most believe that this is necessary: $52.3 \%$ - the ability to make decisions on their own. The need to show perseverance and communication was stated equally by $50 \%$ of students, respectively. The survey data indicate the need for further methodological work on the identified pedagogical and didactic problems.

\section{Discussion}

The analysis of the results of the survey on the blocks of competence R2 "Laboratory medical analysis" indicates that general and professional competencies (GC and PC), as matrices of competencies in the specialty, recorded in the Work programs, are partially formed among 1st-year students. Awareness of the Worldskills Russia movement is low. Only $16.9 \%$ of students were motivated to participate in Worldskills competitions. It is highly important that $89.2 \%$ of students are ready to "learn" to be a professional. The use of a blended learning model, with the transition from passive knowledge acquisition to active activities, individualization of learning when using MOOC resources, the development of communicative competencies in practical classes, indicate the need for further methodological work to explain to students the goals of competitions and prepare for the WSR demo exams.

\section{Conclusion}

The Competition Movement, as one of the legacies of the World Competition in Skills, is an instrument for socio-economic transformation. WSR as part of the international movement, expands the pedagogical potential for the formation of the competencies of students of secondary vocational institutions. The example of a medical college showed that it is possible to combine the content of Worldskills standards, Federal State Educational Standard and professional standards in the field of knowledge, skills and practical experience using blended learning in the field of Chemistry. Formation of professional and "over-professional" competencies of laboratory technicians, whose professional activities are related to clinical, microbiological, immunological and sanitary-hygienic laboratory research, has methodological guidelines for further solving a complex of pedagogical and didactic problems of the competitive movement and exchange of best practices in the field of vocational education.

\section{References}


1. Industry 4.0: Building the digital enterprise. Accessed on: July 20, 2021. [Online]. Available: https://www.pwc.com/gx/en/industries/industries-4.0/landingpage/industry-4.0-building-your-digital-enterprise-april-2016.pdf

2. V.V. Tropnikova, B.I.Shteingolts, Mirovoi opyt realizatsii konkursnogo dvizheniya Worldskills: sushchnost, formy, faktory [World experience in the implementation of the Worldskills competition movement: essence, forms, factors], in Col. of selected articles based on the materials of scientific conferences of the State Research Institute "National Development", St. Petersburg, May 2019, 14-21 (State Research Institute "National Development", St. Petersburg, 2019)

3. F. Dudyrev, et al., Mod. Anal. Edu. S8(30), 5-44 (2019)

4. K. Tremblay, D. Lalancette, D. Roseveare, Assessment of higher education learning outcomes. AHELO feasibility study report, 1 (2012). Accessed on: July 20, 2021. [Online]. Available: http://www.oecd.org/education/skills-beyondschool/AHELOFSReportVolume1.pdf

5. M. Baethge, et al., PISA-VET. A Feasibility Study (Franz Steiner Verlag, 2006)

6. F.F. Dudyrev, et al., Mod. Anal. Edu. S7(29), 5-47 (2019)

7. S. James, C. Holmes, SKOPE Res. Pap. 112 (2012)

8. Inspiring excellence: a guide to embedding skills competition activity in Apprenticeships and vocational learning. Accessed on: July 20, 2021. [Online]. Available: https://repository.excellencegateway.org.uk/LSIS-Inspiring-Excellenceguide.pdf

9. M. Ismail, M. Nurdin, SSRG Int. J. Indust. Eng. 5(3), 1-6 (2018). https://doi.org/10.14445/23499362/IJIE-V5I3P101

10. L. Pylväs, P. Nokelainen, Int. J. Res. Vocat. Edu. and Train. 4(2), 95-116 (2017). https://doi.org/10.13152/IJRVET.4.2.1

11. R.I. Platonova, V.D. Anisimova, M.M. Olesova, Bul. Chuvash State Pedag. Univ. 4(100), 247-255 (2018)

12. M.S. Dobryakova, I.D. Frumin (eds.), Universalnye kompetentnosti i novaya gramotnost: ot lozungov k realnosti [Universal competences and new literacy: from slogans to reality] (Publ. H. of HSE, Moscow, 2020)

13. E.S. Malinovsky, Prof. Edu. Labor Market 3, 38-43 (2018)

14. L.G. Alsynbaeva, Kaliningrad Edu. Bul. 3, 4-12 (2019)

15. M.A. Ivanova, E.V. Kuznetsova, Yu.V. Nikonova, Prob. Pedag. 1(46), 104-107 (2020)

16. M. Xu, J.M. David, S.H. Kim, Int. J. Fin. Res. 9(2), 90 (2018). https://doi.org/10.5430/ijfr.v9n2p90 